Central European Journal of Energetic Materials, 2016, 13(2), 411-426

ISSN 1733-7178

e-ISSN 2353-1843

\title{
The Reinforcement of the TNT System by a Newly- designed GAP-based Polyurethane-Urea: a Molecular Simulation Investigation
}

\author{
Wen QIAN ${ }^{1}$, Yuanjie SHU ${ }^{2 *}$, Qing MA ${ }^{1}$, Huarong LI ${ }^{1}$, \\ Shumin WANG $^{3}$, Xizhou $\mathrm{CHEN}^{1}$ \\ ${ }^{1}$ Institute of Chemical Materials, China Academy of Engineering \\ Physics (CAEP), Mianyang 621900, China \\ ${ }^{2}$ Xi'an Modern Chemistry Research Institute, Xi'an 710065, China \\ ${ }^{3}$ Southwest University of Science and Technology, \\ Mianyang 621010, China \\ *E-mail:syjfree@sohu.com
}

\begin{abstract}
A glycidyl azide (GAP)-based polyurethane-urea (PUU) modifier used in the 1,3,5-trinitrotoluene (TNT)-based composite explosive was investigated by molecular simulation. Inter-molecular interactions were investigated using quantum chemistry calculation on the dimer of TNT and GAP-PUU, and attractive forces were found between the two molecules. The cohesive energy densities and the solubility parameters were obtained through molecular dynamics simulations combined with thermodynamic calculations on the TNT and GAP-PUU amorphous cell models, and the miscibility of the modifier in molten TNT was predicted to be good. The interaction energies and the mechanical properties were then obtained by molecular simulations and mechanical calculations on the solid-phase models of the GAP-PUU with TNT along three crystalline directions, and an improvement in the mechanical properties was predicted.
\end{abstract}

Keywords: TNT, GAP, polyurethane-urea, inter-molecular interaction, mechanical property

\section{Introduction}

The 1,3,5-trinitrotoluene (TNT)-based melt-cast explosive is a widely-used composite explosive, it is easily manufactured and loaded [1], but some problems 
still exist. The anisotropic thermal expansions of the explosive crystals in composite systems during heating affect the shape, micro voids and sensitivity properties during the manufacture, detection and storage processes [2-4]; the weak intermolecular interactions between the TNT molecules make the mechanical properties of TNT-based explosives brittle and weak [5]. In order to enhance the properties of TNT-based composite explosives, a reinforcing modifier should be designed and investigated.

Polyurethane (PU) elastomers and energetic co-polymers are commonlyused modifiers for composite explosives. Each kind of modifier has advantages as well as disadvantages. Polyurethane can form a polymeric net or cage, package the explosive particles and absorb TNT exudation. Energetic thermoplastic elastomers can reduce the loss of energy, for example glycidyl azide polymer (GAP) has high energy and good thermal compatibility with TNT [6-9]. However, polyurethane's miscibility with TNT is bad, and will reduce the detonation energy. Energetic thermoplastic elastomers are often too viscous to be machined, and GAP is expensive and needs to be used in a large amount [6-9]. A GAP-based polyurethane, which combines the advantages of both these modifiers can be used as a candidate for a modifier of the TNT-based composite explosive [10]. Furthermore, the carbamido groups in polyurethane-urea (PUU) will give the hard segment more chance to assemble, which in turn could improve the mechanical properties [11].

In order to make reinforcing modifications of TNT-based composite explosives, a kind of GAP-based polyurethane-urea (GAP-PUU) modifier was designed, and molecular simulations and calculations were carried out on the polymeric segment, thermal compatibility of the modifier with TNT was predicted, and the mechanism of the modification was investigated.

\section{Simulation and Calculation Details}

\subsection{Theoretical basis}

\subsubsection{Thermal compatibility}

Because the molten TNT and the amorphous polymeric modifier are complex multi-particle systems, the cohesive energy density $\left(C E D, \mathrm{~J} / \mathrm{cm}^{3}\right)$ is used to judge the inter-molecular interactions, and the solubility parameter $\left(\delta,\left(\mathrm{J} / \mathrm{cm}^{3}\right)^{1 / 2}\right)$ is defined as [12]: 


$$
\delta=\sqrt{E_{\mathrm{coh}} / V}, E_{\mathrm{coh}}=\Delta H_{\mathrm{v}}-R T, C E D=E_{\mathrm{coh}} / V_{\mathrm{m}}
$$

where $\Delta H_{\mathrm{V}}$ is the heat of vaporization per mole $(\mathrm{kJ} / \mathrm{mol}), R$ is the ideal gas constant $(\mathrm{J} /(\mathrm{mol} \cdot \mathrm{K})), T$ is the temperature $(\mathrm{K})$, and $V_{\mathrm{m}}$ is the molar volume $\left(\mathrm{cm}^{3} / \mathrm{mol}\right)$. When TNT is mixed with the modifier, the heat of mixing $\left(\Delta H_{\mathrm{m}}, \mathrm{kJ} / \mathrm{mol}\right)$ can be described by the semi-empirical Hildebrand equation:

$$
\Delta H_{\mathrm{m}} /\left(V \varphi_{1} \varphi_{2}\right)=\left(\delta_{1}-\delta_{2}\right)^{2}
$$

where $V$ is the total volume, $\varphi_{1}$ and $\varphi_{2}$ are the volume percentages ( $\left.\%\right)$, and $\delta_{1}$ and $\delta_{2}$ are the solubility parameters of the two components. A spontaneous process needs a negative free energy change:

$$
\Delta G_{\mathrm{m}}=\Delta H_{\mathrm{m}}-T \Delta S_{\mathrm{m}}<0
$$

where $\Delta G_{\mathrm{m}}$ is the molar free energy change $(\mathrm{kJ} / \mathrm{mol})$, and $\Delta S_{\mathrm{m}}$ is the molar entropy change $(\mathrm{J} /(\mathrm{mol} \cdot \mathrm{K}))$. If the solubility parameters of the two components are close $\left[\Delta \delta<4\left(\mathrm{~J} / \mathrm{cm}^{3}\right)^{1 / 2}\right]$, the mixture will have thermodynamic compatibility, which is known as the similarity principle of the solubility parameter [12-16].

The thermodynamic parameters, such as cohesive energy and CED can be obtained by thermodynamic analysis of the molecular dynamics (MD) simulation results, from which the solubility parameter can also be calculated. Then the miscibility of the two components can be determined.

\subsubsection{Mechanical properties}

The mechanical parameter calculation is based on Hooke's Law and the stiffness matrix for materials. The generalized Hooke's Law is often written as:

$$
\sigma_{i}=C_{i j} \varepsilon_{j}
$$

where $\sigma_{i}$ is the stress tensor (GPa), $\varepsilon_{j}$ is the strain tensor (GPa), and $C_{i j}$ is the $6 \times 6$ stiffness matrix of elastic constants. If the material is idealized as an isotropic material, the stiffness matrix of the stress-strain behaviour can be fully described by specifying only two independent coefficients (Lamé coefficients) as in Scheme 1, wherein $\lambda$ and $\mu$ are referred to as the Lamé coefficients. 


$\left[\begin{array}{cccccc}\lambda+2 \mu & \lambda & \lambda & 0 & 0 & 0 \\ \lambda & \lambda+2 \mu & \lambda & 0 & 0 & 0 \\ \lambda & \lambda & \lambda+2 \mu & 0 & 0 & 0 \\ 0 & 0 & 0 & \mu & 0 & 0 \\ 0 & 0 & 0 & 0 & \mu & 0 \\ 0 & 0 & 0 & 0 & 0 & \mu\end{array}\right]$

Scheme 1. Stiffness matrix described by the Lamé coefficients.

Thus Young's modulus ( $E, \mathrm{GPa})$, the bulk modulus ( $K, \mathrm{GPa})$, the shear modulus $(G, \mathrm{GPa})$ and Poisson's ratio $(\gamma)$, can be written in terms of the Lamé coefficients as follows $[17,18]$ :

$$
E=\mu\left(\frac{3 \lambda+2 \mu}{\lambda+\mu}\right), K=\lambda+\frac{2}{3} \mu, G=\mu, \quad v=\frac{\lambda}{2(\mu+\lambda)}
$$

The atomic MD simulation is based on microscopic molecular models, however, for the macroscopic explosive crystals, the anisotropy is the same as that of the unit cell, so that the calculated mechanical parameters are meaningful; for amorphous cells, the property is isotropic, so that the mechanical parameters are the same; and as for the mixtures, the real mechanical properties are statistically close to the isotropic properties, thus the parameters from the calculation are still useful.

\subsection{Structure modelling}

The molecular configuration of the newly-designed GAP-PUU, with 10 repeat units $(n=3, x=10)$, was constructed in the manner of a co-polymer in Materials Studio Modeling [19], then the structure was geometrically-optimized and energy-minimized under the COMPASS (Condensed-phase Optimized Molecular Potentials for Atomistic Simulation Studies) [20] force field. The parameters for the azide groups have been included in the COMPASS force field, and the validity of the force field for the use of azide groups had been confirmed [21]. The optimized structure with minimized energy is shown in Figure 1. 


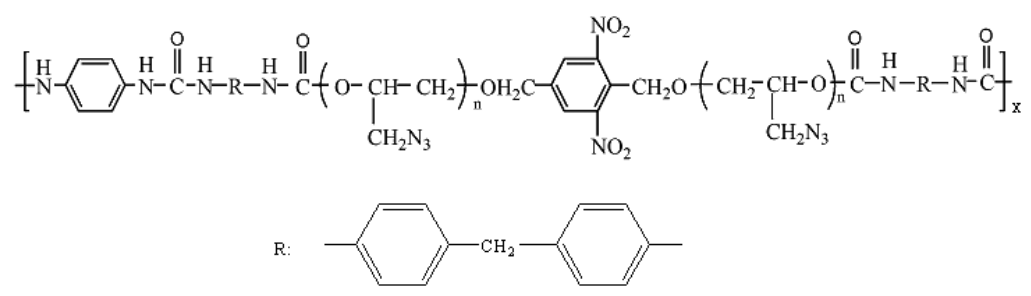

(a)

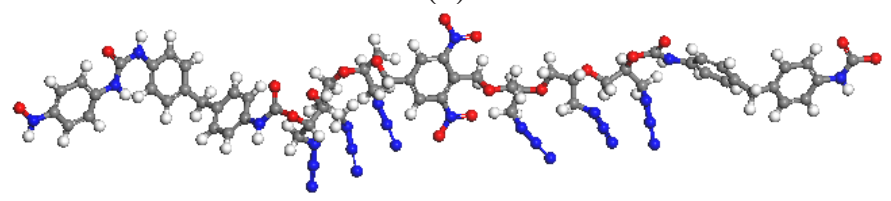

(b)

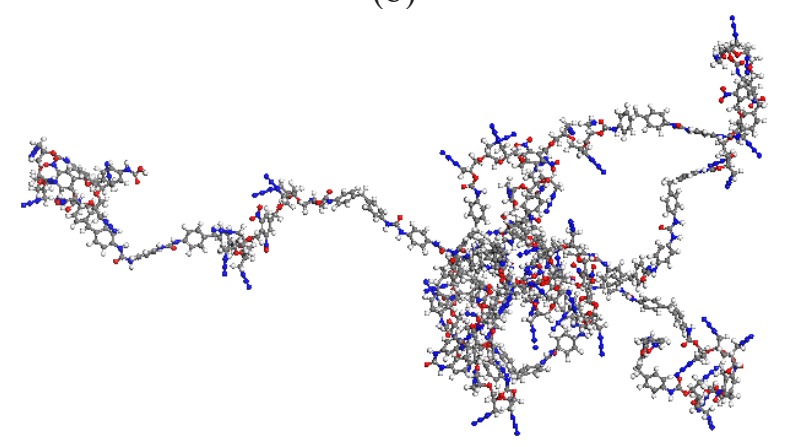

(c)

Figure 1. Molecular model of GAP-PUU: (a) chemical formula; (b) repeat unit; (c) optimized molecular configuration $(\mathrm{x}=10)$.

It can be seen that the newly-designed polymer has energetic segments $\left(-\mathrm{N}_{3}\right)$ to increase the detonation energy, TNT-like segments to improve the miscibility with TNT and carbamido groups to increase the mechanical properties.

The molecular structure of TNT is shown in Figure 2a. The crystal structure of TNT (Figure 2b) was constructed based on Carper's experimental data [22] from the Cambridge Crystallographic Data Center (CCDC), the crystal belongs to the $\mathrm{P}_{\text {ca21 }}$ space group, with cell parameters $a=1.4991 \mathrm{~nm}, b=0.6077 \mathrm{~nm}$, $c=2.0017 \mathrm{~nm}, \alpha=\beta=\gamma=90^{\circ}$. 


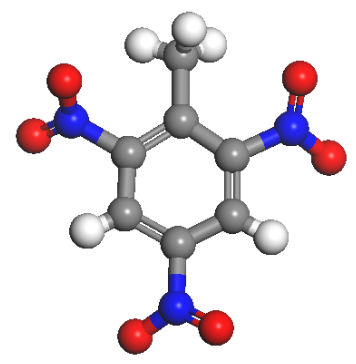

(a)

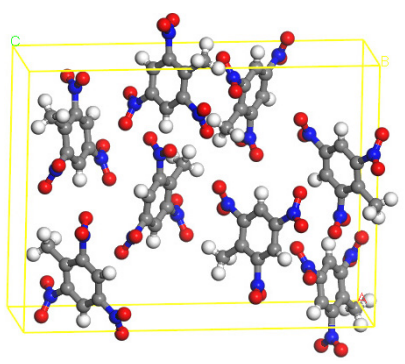

(b)

Figure 2. Molecular model of TNT: (a) molecular configuration; (b) crystalline structure.

\subsection{Inter-molecular interactions and thermal compatibility analysis} The GAP-PUU segment, which contains one repeat unit, was stacked with TNT to form a molecular pair or dimer (Figure 3), the structure was then optimized using the DFT method at GGA/PBE level [23] with DNP basis set, and the process was carried out in $\mathrm{Dmol}^{3}$ module [24]. Thus the details of the inter-molecular interactions can be discussed according to the optimized structure of the dimer.
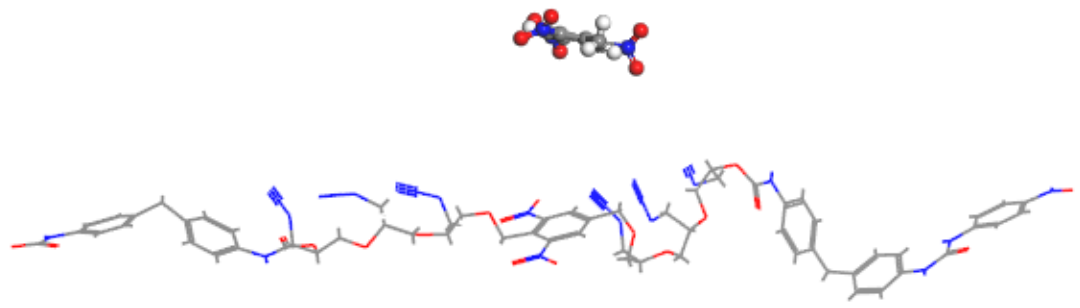

Figure 3. Initial configuration of the TNT-modifier molecular pair.

In order to investigate the miscibility of the GAP-PUU modifier with TNT in the molten phase, the amorphous cell of GAP-PUU was constructed based on the optimized molecule, with a density of $0.8 \mathrm{~g} / \mathrm{cm}^{3}$. Then the structure was geometrically-optimized and energy-minimized; the optimized structure is shown in Figure 4a. The amorphous cell of TNT containing 80 molecules with an experimental molten-phase density of $1.016 \mathrm{~g} / \mathrm{cm}^{3}$, which has a similar number of atoms as the modifier, was also constructed and optimized as shown in Figure 4b. All of the amorphous cells were constructed and optimized under the COMPASS force field; the validation of the forcefield on TNT was confirmed in a previous study [25]. 


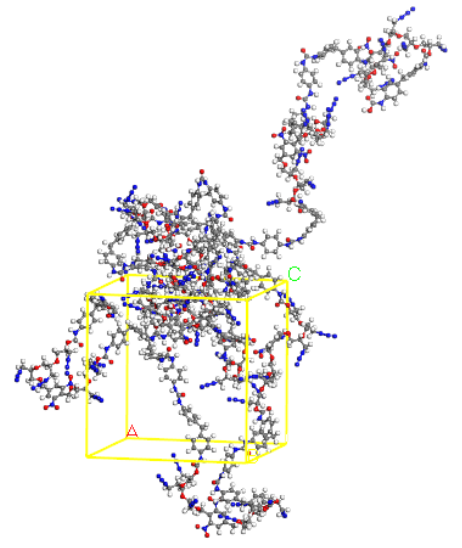

(a)

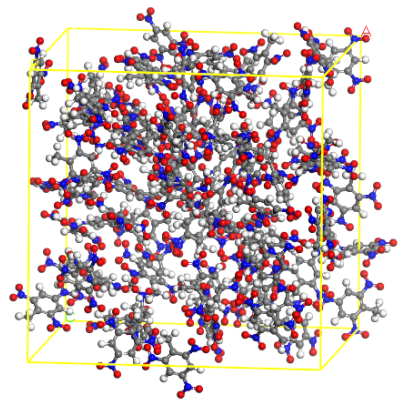

(b)

Figure 4. Amorphous cells of TNT above the melting point: (a) GAP-PUU; (b) TNT $(n=80)$.

MD simulations were carried out on the optimized amorphous cells under the COMPASS force field and the ensemble with constant particle Numbers, Pressure and Temperature (NPT). Velocity Verlet arithmetic [26] was utilized; the initial velocity was sampled by the Maxwell distribution; the van der Waals force was calculated by the atom-based method and coulomb interactions were calculated by the Ewald method [27,28]. To simulate the molten conditions, the target temperature and pressure were set to $354 \mathrm{~K}$ (above TNT melting point) and $100 \mathrm{kPa}$, respectively. The Anderson method [29] was utilized to control the temperature and the Berendsen method [30] was used to control the pressure. Each MD simulation lasted 200 ps with time intervals of 1 fs to ensure the system equilibrated properly, both in energy and temperature. The equilibrium trajectory documents were selected to analyze the thermodynamic properties, such as cohesive energy and $C E D$, and the solubility parameter could be calculated. Thus the miscibility of GAP-PUU with molten TNT can be predicted.

\subsection{Simulation and calculation of the mechanical reinforcement}

In order to investigate the reinforcement of the GAP-PUU modifier, a $2 \times 5 \times 2 \mathrm{TNT}$ supercell was constructed based on the TNT primitive cell. The supercell was then cleaved along three different crystal faces (100), (010) and (001). The optimized GAP-PUU segment with density $0.8 \mathrm{~g} / \mathrm{cm}^{3}$ together with a $5 \mathrm{~nm}$ vacuum layer was placed on each crystalline direction to construct the interface solid models. The dimensions of the interface models, as shown in Figure 5, were $29.982 \mathrm{~nm} \times 30.285 \mathrm{~nm} \times 177.923 \mathrm{~nm}, 40.034 \mathrm{~nm} \times 29.982 \mathrm{~nm} \times 144.592 \mathrm{~nm}$, 
$30.385 \mathrm{~nm} \times 40.034 \mathrm{~nm} \times 152.630 \mathrm{~nm}$, respectively. The structures were optimized by molecular mechanics (MM) and energy-minimized.

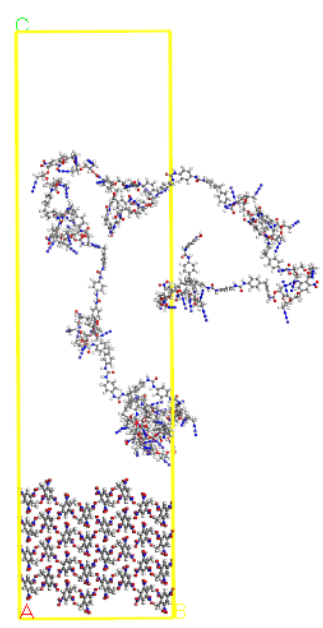

(a)

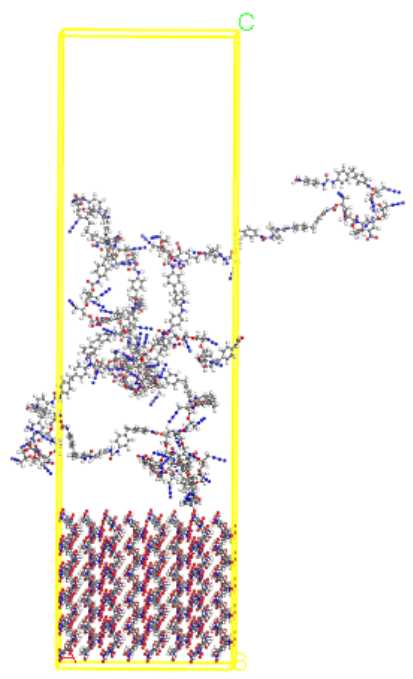

(b)

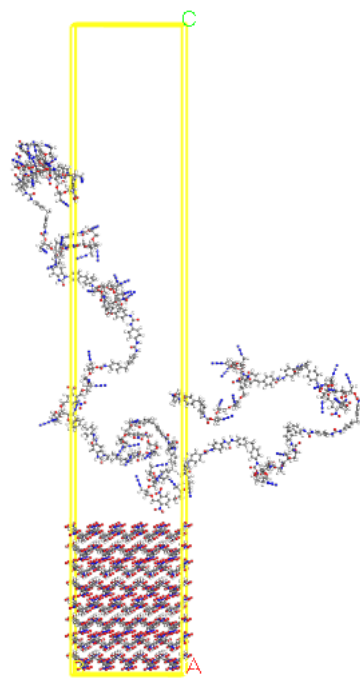

(c)

Figure 5. Solid molecular models of TNT/GAP-PUU: (a) along TNT $\left(\begin{array}{lll}1 & 0 & 0\end{array}\right)$; (b) along TNT ( $\left.\begin{array}{lll}0 & 1 & 0\end{array}\right)$; (c) along TNT ( $\left(\begin{array}{lll}0 & 0 & 1\end{array}\right)$.

The interaction energies can be calculated from the total energies of the TNT super cell, the GAP-PUU segment and the TNT/GAP-PUU models using the following simplified equation [31]:

$$
E_{\text {inter }}=E_{\text {total }}-\left(E_{\mathrm{TNT}}+E_{\text {modifier }}\right)
$$

where $E_{\text {inter }}$ is the interaction energy, $E_{\mathrm{TNT}}, E_{\text {modifier }}$ and $E_{\text {total }}$ are the total energy of pure TNT, the modifier and TNT/GAP-PUU respectively $(\mathrm{kJ} / \mathrm{mol})$. The contributions of the van der Waals forces and the electrostatic interactions (including hydrogen bonds) were given separately; here hydrogen bonds are a natural consequence of the standard van der Waals and electrostatic parameters and special hydrogen bond functions were not included. The interaction energies were normalized by the cross-sectional area, as shown in the following equation:

$$
E_{\text {inter }}=E_{\text {inter }} / \mathrm{S}
$$

where $E_{\text {inter }}^{\prime}$ is the normalized interaction energy $(\mathrm{kJ} / \mathrm{mol})$, and $\mathrm{S}$ is the crosssection area of the optimized interface model $\left(\mathrm{nm}^{2}\right)$. 
Then MD simulations were performed on the optimized structures under the NPT ensemble with the COMPASS force field. To simulate normal conditions, the target temperature and pressure were set to $298 \mathrm{~K}$ and $100 \mathrm{kPa}$, the Anderson method was used to control the temperature and the Berendsen method was used to control the pressure. The initial velocity was sampled by the Maxwell distribution, and the time interval was $1 \mathrm{fs}$. Each MD simulation lasted 200 ps. To ensure the system equilibrated properly, the equilibrium both in energy and temperature is needed.

The equilibrium trajectory documents were selected for the mechanical property calculations. The optimization process was done before the calculation. The elastic constants were obtained by the mechanical analysis, and then other mechanical parameters such as Young's modulus, the bulk modulus, the shear modulus and Poisson's ratio can all be calculated.

\section{Results and Discussion}

\subsection{Inter-molecular interactions between the GAP-PUU segment and TNT}

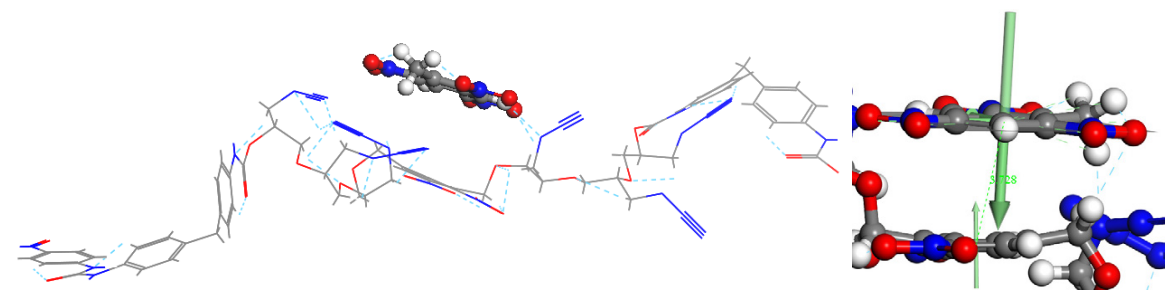

(a)

(c)

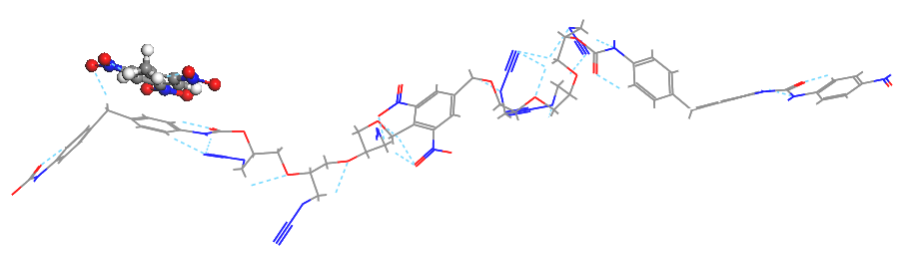

(b)

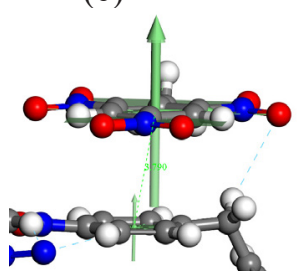

(d)

Figure 6. The hydrogen bond interaction $(\mathrm{a}, \mathrm{b})$ and $\pi-\pi$ conjugation stacking (c, d) between TNT and GAP-PUU.

As shown in Figure $6(a, b)$, a large number of hydrogen bonds (shown in light blue) exist in the optimized structures. Intra-molecular hydrogen bonds exist 
in the TNT and GAP-PUU molecules, which is good for molecular stability. The inter-molecular hydrogen bonds formed between the $\mathrm{O}$ and $\mathrm{N}$ atoms and $\mathrm{H}$ atoms at multiple sites, strengthen the inter-molecular attraction [32]. In addition, the $\mathrm{H}$ atom in the urethano group of GAP-PUU and the $\mathrm{O}$ atom in a nitro group of the explosive can form a coordinate interaction to enhance the inter-molecular attractive force [33].

As shown in Figure 6 (c, d), in the optimized structures, the benzene ring of TNT and that of GAP-PUU stacked almost face to face as the ring-normals of the two benzene-ring planes form angles no greater than $20^{\circ}$, and the centroidcentroid distances of the two benzene-rings are $0.373 \mathrm{~nm}$ and $0.379 \mathrm{~nm}$, respectively, so that the conjugation interaction can be proved according to definitions in the literature $[34,35]$. The existence of $\pi-\pi$ conjugation between the benzene rings will enhance the inter-molecular binding force [34-36].

\subsection{Thermal compatibility of GAP-PUU with TNT}

From the molecular dynamics simulation and thermodynamic analysis of TNT and GAP-PUU at $354 \mathrm{~K}$, the cohesive energy and CED were obtained, and the solubility parameters were calculated, as shown in Table 1.

Table 1. Solubility parameters at $354 \mathrm{~K}$

\begin{tabular}{|l|c|c|}
\hline \multicolumn{1}{|c|}{ System } & $C E D\left[\mathrm{~J} / \mathrm{cm}^{3}\right]$ & $\delta\left[\left(\mathrm{J} / \mathrm{cm}^{3}\right)^{1 / 2}\right]$ \\
\hline TNT & 735.3 & 27.073 \\
\hline GAP-PUU & 567.3 & 23.787 \\
\hline
\end{tabular}

It can be seen that the molecular design improved the solubility value of the PU modifier (since $\delta_{\text {polyurethane }}=20.5\left(\mathrm{~J} / \mathrm{cm}^{3}\right)^{1 / 2}$ in the literature [37]), and the solubility parameters of TNT and GAP-PUU are close, $\Delta \delta=3.286\left(\mathrm{~J} / \mathrm{cm}^{3}\right)^{1 / 2}$; according to the similarity principle of solubility parameter [12-16], the modifier, having relatively good miscibility with TNT, can be mixed in molten TNT.

\subsection{Interface interactions between the TNT system and GAP-PUU}

According to the equilibrium structures, the distance between the GAP-PUU and TNT systems is reduced. The interaction energy can be calculated from the total energy of the equilibrium structures. The results are shown in Table 2. 
Table 2. Interaction energy between the TNT system and GAP-PUU

\begin{tabular}{|c|c|c|c|c|c|c|}
\hline Direction & $\begin{array}{c}E_{\mathrm{TNT}} \\
{[\mathrm{kJ} / \mathrm{mol}]}\end{array}$ & $\begin{array}{c}E_{\text {modifier }} \\
{[\mathrm{kJ} / \mathrm{mol}]}\end{array}$ & $\begin{array}{c}E_{\text {blend }} \\
{[\mathrm{kJ} / \mathrm{mol}]}\end{array}$ & $\begin{array}{c}E_{\text {inter }} \\
{[\mathrm{kJ} / \mathrm{mol}]}\end{array}$ & $S\left[\mathrm{~nm}^{2}\right]$ & $\begin{array}{c}E^{\prime} \text { inter } \\
{[\mathrm{kJ} / \mathrm{mol}]}\end{array}$ \\
\hline $\begin{array}{c}\text { TNT/modifier } \\
(100)\end{array}$ & -1629.46 & -16720.21 & -18885.82 & -536.15 & 8.82 & -60.77 \\
\hline val der Waals & -1173.58 & -12042.36 & -13602.09 & -386.15 & 8.82 & -43.77 \\
\hline Electrostatic & -424.12 & -4351.96 & -4915.63 & -139.55 & 8.82 & -15.82 \\
\hline $\begin{array}{c}\text { TNT/modifier } \\
(010)\end{array}$ & -1629.46 & -16616.41 & -19096.61 & -850.74 & 10.35 & -82.16 \\
\hline val der Waals & -1110.08 & -11320.00 & -13009.64 & -579.57 & 10.35 & -55.97 \\
\hline Electrostatic & -498.93 & -5087.82 & -5847.23 & -260.49 & 10.35 & -25.16 \\
\hline $\begin{array}{c}\text { TNT/modifier } \\
(001)\end{array}$ & -1629.46 & -14117.93 & -16144.92 & -397.53 & 12.75 & -31.19 \\
\hline val der Waals & -1134.31 & -9827.82 & -11238.86 & -276.73 & 12.75 & -21.71 \\
\hline Electrostatic & -485.15 & -4203.45 & -4806.96 & -118.36 & 12.75 & -9.29 \\
\hline
\end{tabular}

It can be seen that strong interface interactions exist between the TNT system and GAP-PUU, where val der Waals (vdW) forces contribute most to the total interactions, and electrostatic interactions also play a main part in the interaction, while other interactions contribute little. Along the different crystal faces, the attraction along (010) is the strongest, while that along (100) and (001) are relatively weak, which may be caused by the different inter-molecular interaction situations along different TNT crystal faces. The particle density on the (001) surface $\left(4.71 \mathrm{~nm}^{-2}\right)$ is smaller than that of the other two directions (14.74 and $13.14 \mathrm{~nm}^{-2}$ ), while the wave-like stacking of the (100) surface makes the interactions along (100) smaller than that along $(010)$, so that both the vdW force and the electrostatic interaction between the modifier and the surface (010) are larger than that on the other two directions, resulting in the total interface interactions being larger than that of the other directions. The layer-like structure of the TNT crystal is the main reason for the anisotropic situations, which matches the situations in the equilibrium structures.

\subsection{The mechanical reinforcement of TNT by the modifier}

The mechanical property calculations and analysis were carried out on the equilibrium structures, the elastic constants $\left(C_{i j}, \mathrm{GPa}\right)$ of pure TNT and solid-state TNT/GAP-PUU under normal conditions along each crystal face were obtained. The results are shown in Table 3. 
Table 3. Elastic constants [GPa] under normal conditions

\begin{tabular}{|c|c|c|c|c|}
\hline Systems & TNT & $\begin{array}{c}\text { TNT/GAP-PUU } \\
(100)\end{array}$ & $\begin{array}{c}\text { TNT/GAP-PUU } \\
(010)\end{array}$ & $\begin{array}{c}\text { TNT/GAP-PUU } \\
(001)\end{array}$ \\
\hline$C_{11}$ & 61.711 & 38.694 & 37.641 & 37.504 \\
\hline$C_{22}$ & 39.811 & 33.605 & 33.781 & 33.303 \\
\hline$C_{33}$ & 47.159 & 36.202 & 36.188 & 36.330 \\
\hline$C_{44}$ & 14.147 & 11.088 & 11.040 & 11.903 \\
\hline$C_{55}$ & 4.919 & 9.051 & 10.073 & 10.599 \\
\hline$C_{66}$ & 19.419 & 12.047 & 11.033 & 11.717 \\
\hline$C_{12}$ & 30.173 & 22.062 & 22.228 & 22.008 \\
\hline$C_{13}$ & 27.046 & 17.771 & 17.097 & 16.644 \\
\hline$C_{14}$ & 0.194 & -0.079 & 0.330 & 0.471 \\
\hline$C_{15}$ & 0.109 & 0.010 & 0.241 & 0.025 \\
\hline$C_{16}$ & -0.010 & 0.034 & -0.495 & 0.482 \\
\hline$C_{23}$ & 40.097 & 21.649 & 21.111 & 21.085 \\
\hline$C_{24}$ & -0.025 & -0.127 & 0.454 & 0.672 \\
\hline$C_{25}$ & -0.050 & -0.125 & 0.358 & 0.360 \\
\hline$C_{26}$ & -0.010 & -0.010 & -0.843 & 0.786 \\
\hline$C_{34}$ & -0.011 & -0.044 & 0.423 & 0.737 \\
\hline$C_{35}$ & 0.086 & -0.031 & 0.470 & 0.341 \\
\hline$C_{36}$ & -0.004 & -0.086 & -0.584 & 0.842 \\
\hline$C_{45}$ & -0.002 & 0.427 & 0.078 & 0.067 \\
\hline$C_{46}$ & 0.024 & 0.152 & -0.062 & 0.042 \\
\hline$C_{56}$ & -0.006 & -0.034 & 0.193 & 0.032 \\
\hline & & & & \\
\hline
\end{tabular}

It can be seen that in the elastic constant matrix, all diagonal elements $C_{i i}$ and the off-diagonal elements $C_{12}, C_{13}, C_{23}$ are larger than the other elements; the other elements are almost zero. The three element groups $C_{11}, C_{22}, C_{33} ; C_{44}, C_{55}, C_{66}$; $C_{12}, C_{13}, C_{23}$ were compared to those of pure TNT, the difference values in each group of the TNT/GAP-PUU's elements being reduced; the equalization of $C_{i j}$ indicates that the addition of the modifier will improve the isotropy of the matrix.

The mechanical parameters of pure TNT and solid-state TNT/GAP-PUU under normal conditions along each crystal face were then calculated and compared; Young's modulus ( $E, \mathrm{GPa})$, the bulk modulus $(K, \mathrm{GPa})$, the shear modulus $(G, \mathrm{GPa})$ and Poisson's ratios $(\gamma)$ are shown in Table 4. 
Table 4. Mechanical properties under normal conditions

\begin{tabular}{|c|c|c|c|c|}
\hline Systems & TNT & $\begin{array}{c}\text { TNT/ } \\
\text { GAP-PUU } \\
(100)\end{array}$ & $\begin{array}{c}\text { TNT/ } \\
\text { GAP-PUU } \\
(010)\end{array}$ & $\begin{array}{c}\text { TNT/ } \\
\text { GAP-PUU } \\
(001)\end{array}$ \\
\hline Young's modulus $(E)[\mathrm{GPa}]$ & 34.004 & 28.499 & 28.425 & 30.065 \\
\hline Bulk modulus $(K)[\mathrm{GPa}]$ & 32.457 & 27.646 & 27.289 & 27.517 \\
\hline Shear modulus $(G)[\mathrm{GPa}]$ & 12.828 & 10.729 & 10.715 & 11.406 \\
\hline Poisson's ratio $(\gamma)$ & 0.325 & 0.328 & 0.326 & 0.318 \\
\hline
\end{tabular}

We have noticed that the parameter values differ from the experimental values in the literature [38]; the differences may arise from the size effect of the micro-scale models and the approximations in the mechanical calculations. Thus the simulated mechanical properties of TNT/GAP-PUU along each crystal face were compared to those of pure TNT. It can be seen that the moduli are reduced, which indicates the attenuation of stiffness, the reinforcement of elasticity and the reduction of brittleness [31]. The Poisson's ratios of TNT/GAP-PUU are all in the range of plastics $0.2-0.4$, indicating good plasticity. So that when GAPPUU is added, the mechanical properties are improved.

\section{Conclusions}

Molecular simulations and calculations were carried out on the newly-designed GAP-PUU modifier and TNT/GAP-PUU systems. The results were as follows.

(1) The dimer of TNT and a GAP-PUU segment was constructed and optimized using quantum chemistry calculations; attractive inter-molecular forces were found according to the $\pi-\pi$ conjugation stacking, hydrogen bonds and coordinate interactions between the two molecules;

(2) The molecular amorphous cells were constructed, the cohesive energies and solubility parameters were obtained by MD simulation and thermodynamic calculation, and the miscibility of the GAP-PUU modifier with molten TNT was predicted to be good;

(3) The solid molecular models of TNT/GAP-PUU along different TNT crystal faces were investigated, the interaction energies were calculated from the total energy of the optimized structures, proving that strong and anisotropic interface interactions exist between the modifier and the TNT system;

(4) MD simulations and mechanical property calculations were carried out on the solid molecular models, and parameters such as elastic constants, Young's modulus, bulk modulus, shear modulus and Poisson's ratios were 
obtained, demonstrating an improvement of the isotropy and a reinforcement of the mechanical properties.

It can be seen that the newly-designed GAP-PUU modifier can be applied in a reinforcing modification of TNT-based composite explosives.

\section{Acknowledgments}

The authors acknowledge the support of the NSFC (National Science Foundation of China) Fund (Grant No. 51373159), the scientific and technical innovation fund from the Institute of Chemical Materials, CAEP (Grant No. KJCX-201409) and the NSAF Fund (Grant No. 11076002). We appreciate the editors and reviewers for their attentive suggestions and works.

\section{References}

[1] Akhavan J., The Chemistry of Explosives, The Royal Society of Chemistry, Cambridge, 2004, pp. 1-20, 118-148; ISBN 978-0-85404-640-9.

[2] Hsueh C.H., Becher P.F., Thermal Stresses Due to Thermal Expansion Anisotropy in Materials with Preferred Orientation, J. Mater. Sci. Lett., 1991, 19(10), 1165-1167.

[3] McGrane S.D., Grieco A., Ramos K.J., Hooks D.E., Moore D.S., Femtosecond Micromachining of Internal Voids in High Explosive Crystals for Studies of Hot Spot Initiation, J. Appl. Phys., 2009, 105(7), 7.

[4] Qian W., Zhang C.Y., Xiong Y., Zong H.H., Zhang W.B., Shu Y.J., Thermal Expansion of Explosive Molecular Crystal: Anisotropy and Molecular Stacking, Cent. Eur. J. Energ. Mater., 2014, 11(1), 569-580.

[5] Shu Y.J., Ma Q., Luo G., Wen M.P., Qian W., Zheng B.H., Cai Z.Z., Li H.R., Chen L., Mechanical Properties Study of Toughened and Modified Melt-Cast TNT Based Explosive Formulations for Anti-Cracks and Brittleness, New Trends Res. Energ. Mater., Proc. Semin., 16 ${ }^{\text {th }}$, Pardubice, Czech Republic, 2013, 331-339.

[6] Voigt H.W., Stanhope R., Cast TNT Explosive Containing Polyurethane Elastomer which is Free from Oily Exudation and Voids and Uniformly Remeltable, US Patent 4012245, 1976.

[7] Stanton H.D., Reed R., Polymer Modified TNT Containing Explosives, US Patent 4445948, 1984.

[8] Willer R.L., Hartwell J.A., Gleeson R.G., High-energy Compositions Having Castable Thermoplastic Binders, US Patent 4889571, 1989.

[9] Ampleman G., Brousseau P., Insensitive Melt Cast Explosive Compositions Containing Energetic Thermoplastic Elastomers, US Patent 2002003016, 2002.

[10] Diaz E., Brousseau P., Ampleman G., Prud'homme R.E., Heats of Combustion and Formation of New Energetic Thermoplastic Elastomers Based on GAP, PolyNIMMO and PolyGLYN, Propellants Explos. Pyrotech., 2003, 28(3), 101-106. 
[11] Herpburn C., Polyurethane Elastomers, (1 ${ }^{\text {st }}$ ed.), Applied Science Publishers, London, 1982; ISBN 978-1851665891.

[12] Hildebrand J.H., Solubility, J. Am. Chem. Soc., 1916, 38, 1452.

[13] Hildebrand J.H., Solubility III: Relative Values of Internal Pressures and Their Practical Application, J. Am. Chem. Soc., 1919, 41,1067.

[14] Scatchard G., Equilibria in Non-electrolyte Solutions in Relation to the Vapor Pressures and Densities of the Components, Chem. Rev., 1931, 8, 321.

[15] Hildebrand J.H., Prausnitz J.M., Scott R.L., Regular and Related Solutions: the Solubility of Gases, Liquids, and Solids, van Nostrand Reinhold Co., New York, 1970, ISBN 978-0442156657.

[16] Brandrup J., Immergut E.H., Polymer Handbook, $3^{\text {rd }}$ ed., John Wiley and Sons Inc., New York, 1989, ISBN 978-0471479369.

[17] Watt J.P., Davies G.F., O’Connell R.J., The Elastic Properties of Composite Materials, Rev. Geophys. Space. Phys., 1976, 14, 541-563.

[18] Weiner J.H., Statistical Mechanics of Elasticity, John Wiley, New York, 1983, ISBN 978-0486422602.

[19] Materials Studio Release Notes, Release 6.1, Accelrys Software Inc., San Diego, 2012.

[20] Sun H., COMPASS: An ab Initio Force-Field Optimized for Condensed-phase Applications, J. Phys. Chem. B, 1998, 102(38), 7338-7364.

[21] Sun H., Rigby D., Development and Validation of COMPASS Force Field Parameters for Molecules with Aliphatic Azide Chains, J. Comp. Chem., 2004, 25(1), 61-71.

[22] Carper W.R., Davis L.P., Extine M.W., Extine M.W., Molecular Structure of 2,4,6-Trinitrotoluene, J. Phys. Chem., 1982, 86, 459.

[23] Perdew J.P., Burke K., Ernzerhof M., Generalized Gradient Approximation Made Simple, Phys. Rev. Lett., 1996, 77, 3865-3868.

[24] Delley B., a) An All-electron Numerical Method for Solving the Local Density Functional for Polyatomic Molecules, J. Chem. Phys., 1990, 92, 508; b) From Molecules to Solids with the DMol ${ }^{3}$ Approach, J. Chem. Phys., 2000, 113, 7756.

[25] Li H.R., Shu Y.J., Gao S.J., Easy Methods to Study the Smart Energetic TNT/ CL-20 Co-crystal, J. Mol. Model., 2013, 19(11), 4909-4917.

[26] Verlet L., Computer Experiments on Classical Fluids I: Thermodynamical Properties of Lennard-Jones Molecules, Phys. Rev., 1967, 159, 98-103.

[27] Ewald P.P., The Calculation of Optical and Electrostatic Lattice Potentials (in German), Ann. Phys. Leipzig., 1921, 64, 253.

[28] Karasawa N., Goddard W.A., Acceleration of Convergence for Lattice Sums, J. Phys. Chem., 1989, 93, 7320-7327.

[29] Andersen H.C., Molecular Dynamics Simulations at Constant Pressure and/or Temperature, J. Phys. Chem., 1980, 72, 2384.

[30] Berendsen H.J.C., Postma J.P.M., van Gunsteren W.F., DiNola A., Haak J.R., Molecular Dynamics with Coupling to an External Bath, J. Chem. Phys., 1984, 81, 3684-3690. 
[31] Qiu L., Xiao H.M., Molecular Dynamics Study of Binding Energies, Mechanical Properties, and Detonation Performances of Bicycle-HMX-based PBXs, J. Hazard. Mater., 2009, 164, 329-336.

[32] Beijer F.H., Kooijman H., Spek A.L., Sijbesma R.P., Meijer E.W., Selfcomplementarity Achieved through Quadruple Hydrogen Bonding, Angew. Chem., Int. Ed., 1998, 37, 75-78.

[33] McNaught A.D., Wilkinson A., IUPAC Compendium of Chemical Terminology, $2^{\text {nd }}$ ed., Blackwell Scientific Publications, Oxford, 1997; ISBN 0-86542-684-8.

[34] Hunter C.A., Sanders J.K.M., The Nature of $\pi-\pi$ Interactions, J. Am. Chem. Soc., 1990, 112(14), 5525-5534.

[35] Janiak C., A Critical Account on $\pi-\pi$ Stacking in Metal Complexes with Aromatic Nitrogen-containing Ligands, J. Chem. Soc., Dalton Trans., 2000, 32(11), 38853896.

[36] Zhang C.Y., Shape and Size Effects in $\pi-\pi$ Interactions: Face-to-face Dimers, J. Comp. Chem., 2011, 32(1), 152-160.

[37] Hansen C.M., Hansen Solubility Parameters: a User's Handbook, $2^{\text {nd }}$ ed., CRC Press, Taylor \& Francis Group, 2007; ISBN 978-0849372483.

[38] Pinto J., Wiegand D.A., Yield and Plastic Flow in Composition B and TNT, US Army, Technical Report ARAED-TR-92024, Picattiny Arsenal, 1993. 